\title{
Transtorno de personalidade borderline ou transtorno afetivo bipolar? Contribuições da Psicopatologia Fenomenológica para o diagnóstico diferencial
}

\author{
Borderline Personality Disorder or Bipolar Affective Disorder? Contributions of \\ Phenomenological Psychopathology to the differential diagnosis
}

\author{
Giuliana Angeli Pieri ${ }^{1}$ \\ Gustavo Bonini Castellana²
}

\section{Resumo}

O diagnóstico de Transtorno de personalidade borderline (TPB) tem sido defendido por alguns autores como um continuum do Transtorno Afetivo Bipolar (TAB). Entre esses autores, Akiskal afirma que tais quadros seriam manifestações sobrepostas de uma tendência comum à ciclotimia. Por outro lado, autores também contemporâneos, como Fuchs, Kimura, Stanghellini e Rosfort, de orientação fenomenológica, apoiam-se no estudo do "vivido" desses pacientes, para diferenciar os fenômenos dos sintomas listados. Conseguem, assim, demonstrar que a "depressão vazia” apresentada nos TPB é fenomenologicamente diferente da "depressão culpada", característica dos melancólicos. O humor disfórico no TPB, por sua vez, diferencia-se da mania por sua força corporal primária, que fragmenta a estrutura intencional da corporeidade. A análise da temporalidade e identidade revela, ainda, que a divisão temporal do self e a fragmentação do self narrativo são as características essenciais do TPB. Esta exploração mostra, assim, como a psicopatologia fenomenológica contribui para o melhor diagnóstico clínico, dirimindo confusões oriundas dos critérios sintomatológicos atuais. Palavras-chave: Borderline; Diagnóstico; Diferencial; Psicopatologia; Fenomenológica

\begin{abstract}
The diagnosis of Borderline Personality Disorder (BPD) has been defended by some authors as a continuum of Bipolar Affective Disorder (BAD). Among these authors, Akiskal has posited that these conditions are overlaid manifestations of a common tendency to cyclothymia. Conversely, other equally contemporary authors such as Fuchs, Kimura, Stanghellini and Rosfort, phenomenology-oriented, differentiate the phenomena of the symptoms listed based on these patients" "lived". Thus, they are able
\end{abstract}


to demonstrate that the "empty depression" presented in BPD is phenomenologically different from the "guilty depression", characteristic of melancholics. In turn, dysphoric mood in BPD differs from BAD due to its primary strength, which fragments the intentional structure of embodiment. The analysis of temporality and identity further reveals that the temporal division of the self and the fragmentation of the narrative self are fundamental characteristics of BPD. Therefore, this exploration shows how phenomenological psychopathology contributes for a better clinical diagnosis, overcoming misconceptions derived from the current symptomatological criteria.

Keywords: Borderline; Diagnosis; Differential; Phenomenological; Psychopathology

${ }^{1}$ Especializanda em Psicopatologia Fenomenológica pela Faculdade de Ciências Médicas da Santa Casa de São Paulo - FCMSCSP - São Paulo, SP, Brasil.

${ }^{2}$ Professor da especialização em Psicopatologia Fenomenológica na Faculdade de Ciências Médicas da Santa Casa de São Paulo - FCMSCSP - São Paulo, SP, Brasil.

Recebido em: 9/10/2016

Aceito em: 29/10/2016 


\section{Introdução}

Atribui-se à influência dos trabalhos de Kurt Schneider, em 1923, o conceito de transtorno de personalidade, expresso até hoje nas classificações psiquiátricas oficiais (OMS, 1997; APA, 2014). Contudo, ao contrário das classificações atuais, baseadas em critérios e categorias isoladas, Schneider propunha uma abordagem prototípica, descrevendo dez subtipos de "personalidades psicopáticas", em que a personalidade seria psicopática quando, "em consequência de sua anormalidade, sofre ou faz sofrer" (Schneider, 1980). Constituiriam, de qualquer forma, quadros psicopatológicos de desenvolvimento, diferentes dos processos psíquicos, cujo maior representante é a esquizofrenia (Jaspers, 1979; Tamelini, 2013).

A personalidade borderline, especificamente, referia-se mais a uma estrutura psíquica vulnerável do que a uma entidade nosológica típica. Na tradição psicanalítica, o termo é frequentemente utilizado pelo conjunto de operações defensivas comuns, que refletem uma estrutura psíquica vulnerável, que funcionaria de maneira "instavelmente estável", entre a neurose e a psicose. Tal conceptualização abrangeria um largo território psicopatológico, incluindo alterações afetivas, neuróticas e perversas (Dalgalarrondo \& Vilela, 1999; Kimura, 1998).

Já as classificações psiquiátricas contemporâneas, propõem a realização do diagnóstico por meio da soma de sintomas. Se o paciente "se encaixa" em um determinado número de sintomas descritos, é diagnosticado como portador de um transtorno. Assim sendo, é provável - e corriqueiro - que um mesmo paciente, avaliado por diferentes examinadores, seja diagnosticado de maneiras diversas, já que o mesmo sintoma psiquiátrico pode aparecer isolado, em síndromes, doenças, processos e reações (Sonenreich, Kerr-Corrêa \& Estevão, 1991).

$\mathrm{Na}$ abordagem nosográfica atual, o Transtorno de personalidade borderline (TPB) é definido como um "padrão invasivo de instabilidade dos relacionamentos interpessoais, autoimagem e afetos, e acentuada impulsividade, que começa no início da idade adulta e está presente em uma variedade de contextos" (OMS, 1997).

Tal definição refere-se, assim, a um construto definido operacionalmente, no qual o paciente é classificado como sendo borderline se preencher alguns critérios de sintomas estabelecidos. Esta operacionalização tem a ambição de dar mais confiabilidade, permitindo maior homogeneidade entre os avaliadores, embora perca em validade (Kraus, 2003). 
Afeitos aos trabalhos de Kraepelin, alguns autores têm defendido a tese de que os transtornos da personalidade são manifestações frustras das grandes síndromes psiquiátricas, com as quais estabeleceriam um continuum entre si, e as variações normais do comportamento (Tavares \& Ferraz, 2011).

De acordo com Akiskal (2004), um dos maiores representantes desta corrente de pensamento, tal posição seria mais compatível com as formulações psicobiológicas, que posicionam esse transtorno na fronteira com doenças, como a esquizofrenia, o Transtorno afetivo bipolar (TAB) e as psicoses epilépticas. O TPB, então, seria uma forma frustra de psicoses endógenas, tais como transtornos "subesquizofrênicos", "subafetivos" ou "subictais".

Cria-se, assim, uma celeuma entre os psiquiatras, opondo aqueles que mantêm uma orientação sintomatológica-criteriológica (Kraus, 1994) e defendem a presença de um continuum entre os quadros de TPB e TAB e aqueles de orientação fenomenológicaantropológica, para quem o fenômeno expressa o vivido do paciente, revelando estruturas radicalmente diferentes.

Como ficará evidente neste artigo, nosso posicionamento alinha-se com a tradição fenomenológica; procuraremos demonstrar, portanto, as contribuições dos autores desta tradição para esse importante diagnóstico diferencial na clínica psiquiátrica contemporânea. Primeiramente, faz-se necessário explorar com mais profundidade a oposição instalada e o trabalho desenvolvido por seus respectivos autores.

\section{Depressão borderline e melancólica: divergências entre o diagnóstico criteriológico e fenomenológico}

Entre os autores de orientação sintomatológica-criteriológica, Akiskal (2004) tem defendido a ideia de que, em uma parcela significativa dos pacientes com TPB, a labilidade do humor e as avalanches emocionais de hostilidade que os caracterizam seriam derivadas de tal desregulação do temperamento de natureza essencialmente afetiva.

Seguindo esta linha de pesquisa, Perugi, Fornaro e Akiskal (2011) sugerem que a depressão atípica, o transtorno de personalidade borderline e o transtorno bipolar do tipo II seriam manifestações sobrepostas de uma tendência comum à ciclotimia. $\mathrm{O}$ termo "depressão atípica" incluiria um grande subconjunto de estados depressivos, 
caracterizados pela presença de reatividade do humor, padrão de sensibilidade interpessoal, identificado por vulnerabilidade exagerada a sentir-se ferido ou magoado por críticas ou rejeições e sintomas vegetativos reversos, como aumento do apetite e hipersonia.

Para esses autores, tais achados concordariam com a observação de que características borderline estão relacionadas à instabilidade do humor do tipo chamado ciclotímico. A presença de atributos ciclotímicos explicaria a maior parte da relação entre depressão atípica e transtorno de personalidade borderline, incluindo os esforços para evitar o abandono, relacionamentos instáveis, confusão da identidade, impulsividade, comportamento automutilador, reatividade e irritabilidade do afeto. Tal concepção, obviamente, implicaria no tratamento destes pacientes:

considerar a presença de uma forma branda de bipolaridade em tais pacientes borderline-depressivo atípicos seria importante para protegê-los de possíveis viradas de humor induzidas por antidepressivos, bem como de ciclagem rápida, e evitar comportamentos impulsivos e agressivos causados por tais alterações do humor (Perugi, Fornaro \& Akiskal, 2011, p. 50).

Para Akiskal (2004), a afetividade deve ser considerada de forma dimensional e alterações do humor, ocorrendo em horas ou em um ou dois dias (o que seria presumivelmente patognomônico para $\mathrm{TPB}$ ), revelam um continuum com o transtorno bipolar do tipo II, definido por uma hipomania mais sustentada. O TPB, por este motivo, não teria um perfil único e distinto dos transtornos afetivos, como é atualmente conceituado.

Para a orientação sintomatológica-criteriológica, portanto, o TPB e o TAB fariam parte de um mesmo "espectro", no qual a tensão e a irritabilidade, superpostas a paroxismos de raiva, caracterizariam os "quadros mistos" - também chamados de “depressão excitada" ou “depressão durante a mania” (Moreno \& Moreno, 2005), por serem marcados por sintomas depressivos associados à agitação psicomotora.

Contrapondo a visão de Akiskal, autores da tradição fenomenológica mostram a necessidade de exploração profunda da experiência subjetiva de pessoas deprimidas, para só assim aventarem a discriminação das diferentes formas de depressão.

Tonus, Estevão e Sonenreich (2012), citando Shorter (2007), argumentam que há uma clara distinção entre a depressão melancólica e não melancólica, esta última 
sendo composta pela depressão neurótica/reativa e vista conjuntamente com transtornos ansiosos e de personalidade, nos quais se incluem os TPB.

Esses mesmos autores criticam o fato do Diagnostic and Statistical Manual of Mental Disorders (DSM-III) (1980) ter cometido "o erro de associar o volumoso campo das duas depressões na forma de depressão maior, "conceito que engloba entidades psicopatológicas que gerações precedentes de clínicos e nosológicos esforçaram-se para manter separadas" (Tonus, Estevão \& Sonenreich, 2012, p. 108). De acordo com Western et al. (1992), citados por Stanghellini \& Rosfort (2013), a depressão "vazia" de pacientes borderline é caracterizada por sentimentos de vazio, solidão e desespero, em relação às pessoas pelas quais têm apego, associados a uma afetividade lábil, e centraliza-se sobre preocupações com abandono e rejeição.

Já a depressão "culpada" - que reflete as formas mais clássicas de transtornos de humor - apresenta, como tema fundamental, a culpa e, como principais características, a falta de energia vital e a sensação de perda de ressonância ("sentimento de falta de sentimento"). Esta síndrome depressiva reflete o protótipo tradicional de depressão ou melancolia, descrita e discutida por Tellenbach, que associou a melancolia a um tipo específico de personalidade, denominado Typus Melancholicus (Kraus, 1987).

Os autores apontam, ainda, que, enquanto o sentimento de culpa nos melancólicos tende a evocar a vergonha quando pensam na pessoa à qual fizeram mal, nos pacientes borderline, a "culpa persecutória" é caracterizada por uma sensação de terem sido humilhados pelo outro. Assim, culpa e vergonha nos melancólicos são autorreferenciais: sentem-se culpados e envergonhados de si mesmos. Já a culpa persecutória e a humilhação em pacientes borderline envolvem o outro: sentem-se injustiçados e humilhados pelo outro, que é o responsável por revelar os seus erros a todos e por estabelecer falhas morais em seu caráter.

Por isso, geralmente o fator desencadeante da depressão no paciente melancólico é a experiência de perda, interpretada como causada por seu próprio comportamento errado, enquanto o paciente borderline é sensível às experiências de abandono, interpretadas como causadas pelo comportamento errado da outra pessoa.

Assim, os critérios diagnósticos, embora possam convergir nos quadros depressivos melancólico e borderline, apresentam características bastante diferentes, que ficam evidentes no relato dos próprios pacientes sobre suas vivências. Tais 
diferenças ficarão ainda mais evidentes ao aprofundarmos a análise fenomenológica dos pacientes borderline em seu modo de ser-no-mundo.

\section{Intersubjetividade}

Para Stanghellini e Rosfort (2013), a raiva e a disforia são as emoções essenciais que caracterizam as pessoas borderline. Para eles, a disforia é um traço permanente no borderline - mais que isso, o complexo emocional disfórico (disforia, irritabilidade, agitação interna, labilidade emocional) é o traço de humor que tipifica o borderline. É a tonalidade emocional profunda e duradoura, o temperamento básico, no qual o borderline é capturado. É um estado emocional repleto de sentimentos, sem um objeto específico, um estado de tensão que pode levar a explosões vigorosas, bem como à estagnação ou depleção emocional.

Já a raiva, é um estado agudo intermitente, o estado afetivo que pontua a existência do borderline. Explosões de raiva, emanando da disforia de base, são associadas a sentimentos de humilhação e podem gerar episódios micropsicóticos incluindo fenômenos delírios-like e alucinatórios-like.

Estas características não devem ser confundidas com a irritabilidade presente, muitas vezes, no paciente maníaco, para quem os temas não têm peso, não são corporificados. Sonenreich, Kerr-Correa e Estevão (1991) lembram que o paciente, em mania, pode falar de morte, desastres, doenças, calamidades e ameaças, mas a velocidade do curso do pensamento faz com que o peso dado a tais conteúdos seja menor, transitório. A aceleração impede que os pensamentos dolorosos se instalem, dominem e tomem proporções consideráveis. A velocidade diminui ou anula o peso do sofrimento e, em geral, o peso de qualquer vivência.

A disforia fragmenta a experiência de si e de outros e contribui para o sentimento doloroso de incoerência e vazio interior: "na atmosfera confusa de seu humor disfórico, o paciente borderline sente seu próprio self como turvo e vago, sentese desprovido de uma identidade definida, é incapaz de envolver-se de maneira constante em um projeto de vida ou em algum papel social" (Stanghellini \& Rosfort, 2013, p. 16).

A raiva aparece, então, como uma forma de restaurar a coesão do self, dissipando a atmosfera confusa da disforia e formando uma imagem do outro mais nítida, embora representando-o como objeto ameaçador. Por isso, "a raiva tende a 
preservar e manter uma coesão precária do self; descarregar a raiva é, portanto, uma forma de sentir-se vivo e afirmar o próprio direito de existir como uma pessoa única" (Stanghellini \& Rosfort, 2013, p. 16). Assim, os autores esclarecem que, no paciente borderline, a raiva tem um papel na busca da estabilização da identidade:

durante episódios de raiva, os valores e normas vagos e confusos que caracterizam a existência borderline são subitamente substituídos por um universo claro, no qual é dolorosamente óbvio à pessoa borderline quem é "bom" (ele mesmo) e quem é "mau" (o outro). Tal sentimento de infalível legitimidade ajuda a pessoa borderline a encontrar sua identidade perdida em um mundo que, momentaneamente, recupera sua estrutura e seu sentido (p. 16) ${ }^{1}$.

\section{Corporeidade}

Stanghellini e Rosfort (2013) relatam que, enquanto a corporeidade, nos melancólicos, é dominada pela superidentificação - eles sentem que não são nada além do próprio corpo, vivido como algo materializado, pesado, rígido e desprovido de emoções, energias e impulsos -, nas depressões borderline existe a sensação de uma energia incontrolável, que dissipa o sentimento da pessoa de ser agente de si mesma e pode terminar em completa exaustão e prostração. Os autores explicam que

o corpo próprio, como fonte de vitalidade e impulso, é sentido como se ausente de controle voluntário, estando em algum lugar entre o self e algo que não é o self. "O corpo é, então, sentido como se carregado de uma energia que parece não pertencer a si mesmo, ou seja, que desfaz a sensação da pessoa de ser si mesma, transformando-o em uma fonte de vitalidade anônima" (p. 6).

Assim, reações corporais dominam as ações corporais e o sentimento íntimo do ser corporificado é eclipsado pela sensação de ter um corpo intimidador. Tal vitalidade caótica, desprovida de uma estrutura intencional e de conteúdo, persegue desesperadamente um objeto, na maioria das vezes, uma outra pessoa, à qual dirigir tal excesso de energia. Frequentemente, tal impulso toma um aspecto sexual, que o borderline chama de "amor".

A normatividade emocional do borderline é constituída pela intensidade de seus valores afetivos, que são constantemente frustrados pelas normas éticas e sociais que

\footnotetext{
${ }^{1}$ Tradução livre dos autores, bem como nos demais trechos citados do mesmo artigo.
} 
estruturam o mundo em que vive. O borderline não consegue manter seus acessos de energia restritos ou conformados às necessidades de pessoas, normas, ou convenções sociais, as quais considera como inautênticas e como um desafio à sua verdadeira natureza e a sua espontaneidade. Muitas vezes, tal normatividade emocional frustrada pode ser a causa inicial de uma depressão borderline.

Sentimentos e valores são, portanto, a mesma coisa para o borderline. A incapacidade de distanciar-se de seus próprios sentimentos significa que o borderline não consegue apropriar-se de tais sentimentos à luz das normas, que são parte de um mundo compartilhado com outras pessoas. Ele é condenado a viver a intensa, porém rompida, vida de seus sentimentos.

Trata-se, concluem Stanghellini e Rosfort (2013), de uma vitalidade desesperada, que produz um tipo complexo de depressão, caracterizado pelo vazio, preocupações com abandono e rejeição, desespero e falta de sentido, um sentimento de identidade lábil e uma emocionalidade difusa e negativa, constantemente pontuada por sentir-se humilhado e marcado por explosões de agressividade.

\section{Temporalidade}

Segundo Paul Ricoeur (1992), citado por Fuchs (2007), a essência do ser humano encontra-se no relacionamento temporal que temos com nós mesmos:

pessoas não são apenas coisas no mundo que se caracterizam por permanecer as mesmas ao longo do tempo, pela mera constância de seus nomes, corpos ou caracteres. A pessoa é, antes, alguém que age e fala e, ao fazer isso, prova ser alguém que compreende a si mesmo e que se relaciona consigo mesmo (p. 380) ${ }^{2}$. Ricoeur argumenta ainda que "somente eu posso ser responsável por atos praticados por mim no passado, e que me mantenho sendo eu mesmo ao ser fiel às minhas promessas no futuro" (p. 380), e por isso chama este tipo de identidade histórica ou temporal de "ipse identidade" ou "ipseidade".

Tais conceitos de responsabilidade e promessa são princípios da identidade que estão relacionados ao outro, à pessoa pela qual somos responsáveis e a quem nos dirigimos, seja ela real ou imaginária.

\footnotetext{
${ }^{2}$ Tradução livre dos autores, bem como dos demais trechos citados do mesmo artigo.
} 
Fuchs (2007) argumenta então que há sempre um outro implícito, para quem presto contas do que faço e que é uma testemunha de minhas ações e intenções. Este outro implícito também seria o ouvinte para quem conto a minha história, a minha narrativa, e demonstro, assim, o nexo entre meu passado, presente e futuro.

Tais conceitos caracterizam o segundo aspecto da identidade, a identidade narrativa, onde o outro é o ouvinte dessa história, mas, também, seu coautor, uma vez que identidades pessoais são constituídas pela interação entre perspectivas em primeira, segunda e terceira pessoas. A ideia de identidade narrativa tem como premissa que o sujeito seja capaz de conectar aspectos contraditórios de sua própria história, em uma narrativa coesa.

Para Fuchs (2007), os pacientes com transtorno de personalidade trocam de um ato presente para o próximo, sendo totalmente identificados com seu estado ou afeto momentâneos, o que resulta em uma divisão temporal do self, que tende a excluir passado e futuro como dimensões de constância, comprometimento, responsabilidade e identidade. Esta identidade fragmentada, pouco coesa, aparece também na dificuldade de relatarem fatos de seu passado, narrando suas histórias com enormes lacunas e inconsistências.

Assim, para Fuchs (2007), indivíduos borderline apresentam uma fragmentação do self narrativo (p. 381), e por isso não tem a experiência de autoria de sua própria vida, e são apenas o que experimentam no exato momento, num presente intenso, vazio e superficial" (p. 381).

Esta estrutura temporal particular implica em uma busca constante de momentos prazerosos, emoções e êxtase com o objetivo preencher a lacuna e o vazio criados pela ausência de integração da experiência passado e da antecipação do futuro, caracterizando aquilo que Kimura chamou de "temporalidade intra-festum".

Conforme Kimura (1998), “o indivíduo borderline é absorvido na presença dos objetos e não procura instaurar entre ele e seus objetos nenhuma relação" (p.25) ${ }^{3}$. Esta falha da coesão temporal aparece também na dificuldade de relatarem fatos de seu passado, narrando suas histórias com enormes lacunas e inconsistências. Fuchs (2007) chamou esta característica de "incoerência da memória autobiográfica" e relacionou

\footnotetext{
${ }^{3}$ Tradução livre dos autores, bem como dos demais trechos citados do mesmo artigo.
} 
esta dificuldade também à tendência que tais pacientes têm em dissociar, que teriam origem nas

experiências traumáticas armazenadas na memória como fragmentos sensoriais sem coerência narrativa e, quando há a subsequente falha em ativar tais lembranças, a dissociação aparece. Assim, se por um lado a dissociação "protege" o indivíduo de sentir sensações ruins relacionadas a estas lembranças traumáticas, por outro lado, tornam a narrativa histórica incoerente, cheia de falhas e lacunas (Fuchs, 2007, p.382).

\section{Identidade}

Como resultado dessa fragmentação do self narrativo, os pacientes borderline apresentam uma visão inconstante de si mesmos, com descontinuidades nos relacionamentos e papéis desempenhados e um sentimento subjacente de vazio interior. Não havendo senso de continuidade temporal, não há que se falar em desenvolvimento do self projetado no futuro, mas "tão somente uma repetição sem fim dos mesmos estados afetivos, criando um peculiar modo atemporal de existência" (Fuchs, 2007, p. $382)$.

Assim, este modo de ser dependente do estado afetivo presente, leva esses pacientes a uma vida carente de planos em longo prazo e de continuidade em sua história. São pessoas que estão frequentemente mudando seus empregos, relacionamentos e, até mesmo, seus valores e objetivos. Os próprios pacientes vivenciam essa falta de coesão em sua história e sentem-se inautênticos, "como se estivessem fingindo ser quem são e como se estivessem enganando as outras pessoas" (Fuchs, 2007, p. 382).

Fuchs entende, também, que esse distúrbio da identidade no indivíduo borderline está relacionada com as oscilações extremas de humor, que fazem com que o paciente se sinta quase como se fosse várias pessoas diferentes, cada uma definida por um estado particular do humor, ao ativar memórias relacionadas àquele afeto.

A vida torna-se, assim, uma série de episódios com pouca coesão entre si e as pessoas que entram e saem de suas vidas uma sucessão sem fim, o que resultaria na falta de memórias intersubjetivas compartilhadas, um motivo adicional para o senso incompleto de identidade. Por outro lado, sentir tal falta de identidade interior pode levar ao medo desesperado do abandono e às tentativas para evitar 
tal abandono... Quando o outro é necessário para estabelecer um frágil sentido de continuidade e coerência - mesmo que seja apenas servindo como um portador dos afetos negativos intoleráveis projetados a ele - então a ameaça do abandono evoca a perda do próprio sentido de si mesmo (Fuchs, 2007, p. 383).

\section{Discussão}

O rigor psicopatológico se faz necessário para aprimorar a validade do diagnóstico psiquiátrico, direcionando para o melhor tratamento psicofarmacológico e psicoterapêutico. A confusão diagnóstica costuma trazer graves prejuízos aos pacientes, levando à indicação de tratamentos ineficazes e por vezes danosas.

Como lembram Bloc \& Moreira (2013), ao analisar a obra de Arthur Tatossian, a psicopatologia fenomenológica "assume assim um posicionamento crítico de questionar a rapidez e a precocidade do diagnóstico e a postura muitas vezes estática da psiquiatria" (p.32).

O diagnóstico fundamentado na psicopatologia fenomenológica parte da experiência vivida e narrada pelos pacientes, e do julgamento fenomênico que o psicopatologista faz dessa experiência em sua interação com o paciente (Serpa, 2007). Seu método é, portanto, a descrição "rigorosa, aprofundada, refinada e próxima das especificidades individuais" que visa clarear a estrutura que subjaz aos sintomas apresentados (Barthélémy, 2012, p.96).

Para demonstrar como estes quadros têm sido estudados na tradição fenomenológica, optamos aqui pela divisão dos fenômenos nas categorias intersubjetividade, corporeidade, identidade e temporalidade, embora fique evidente a relação entre cada uma destas categorias. Essa exploração permitiu concluir que, embora apresentem sintomas e critérios que se sobrepõem na clínica, os indivíduos borderline apresentam um modo próprio de ser-no-mundo.

\section{Considerações finais}

A ideia de que existe uma continuidade psicopatológica entre o Transtorno Afetivo Bipolar e o Transtorno de Personalidade Borderline parece refletir de forma paradigmática os problemas advindos da psicopatologia sintomatológica-criteriológica. A importância da psicopatologia fenomenológica, ao considerar as vivências subjetivas, 
reside não somente em favorecer o humanismo na psiquiatria, mas principalmente em aprimorar o diagnóstico e, consequentemente, o tratamento dos transtornos mentais. 


\section{Referências}

Akiskal, H. S. (2004). Demystifying borderline personality: critique of the concept and unorthodox reflections on its natural kinship with the bipolar spectrum. Acta Psychiatrica Scandinavica, 110(6), 401-407.

American Psychiatric Association (APA) (2014). Manual diagnóstico e estatístico de transtornos mentais $5^{a}$ edição (DSM-5). Porto Alegre: Artmed.

Barthélémy, J. M. (2012). Origem e contexto de emergência da noção de estrutura em Psicopatologia Fenômeno-Estrutural: evolução do conceito, seu lugar e suas implicações nas práticas clínicas contemporâneas. Revista Psicopatologia Fenomenológica Contemporânea, 1 (1), 88-105.

Bloc, L., \& Moreira, V. (2013). Sintoma e fenômeno na psicopatologia fenomenológica de Arthur Tatossian. Revista Latinoamericana de Psicopatologia Fundamental, 16(1), 28-41.

Dalgalarrondo, P., \& Vilela, W. A. (1999). Transtorno borderline: história e atualidade. Revista Latinoamericana de Psicopatologia Fundamental, 2(2), 52-71.

Fuchs, T. (2007). Fragmented selves: temporality and identity in borderline personality disorder. Psycopathology, 40(6), 379-387.

Jaspers, K. (1979[1913]). Psicopatologia geral (2a ed., Vols. 1-2). São Paulo: Atheneu.

Kimura, B. (1998). Fenomenologia da depressão estado-limite. Revista Latinoamericana de Psicopatologia Fundamental, 1(3), 11-32.

Kraus, A. (1987). Comparacion fenomenológica entre la estrutura de la histeria y de la melancolia. In: Barcia, D. (ed), Psiquiatria antropológica (pp.71-88). España: Secretariado de publicaciones e intercambio cientifico de la Universidade de Murcia.

Kraus, A. (1994). Phenomenological and criteriological diagnosis: different or complentary? In: Sadler, J. Z.; Wiggins, P. W., Schwartz, M. A. Philosofical Perspectives on Psychiatric Diagnostic Classification (pp.148-160). Baltimore: The John Hopkins University Press.

Kraus, A. (2003). How can the phenomenological anthropological approach contribute to diagnosis and classification in psychiatry? In: Fulford, B., Morris, K., Sadler, J., G. Nature and narrative: an introduction to the new philosophy of psychiatry (International Perspectives in Philosophy and Psychiatry) (pp. 199-218). Oxford: Oxford University Press. 
Moreno, D. H., Moreno, R. A. (2005). Estados mistos e quadros de ciclagem rápida no transtorno bipolar. Revista de Psiquiatria Clínica, 32(Supl 1), 56-62.

Organização Mundial da Saúde (OMS) (1997). Classificação Estatística Internacional de Doenças e Problemas Relacionados à Saúde 10a rev (CID-10). São Paulo: Universidade de São Paulo.

Perugi, G., Fornaro, M., \& Akiskal, H. S. (2011). Are atypical depression, borderline personality disorder and bipolar II disorder overlapping manifestations of a common cyclothimic diathesis? World Psychiatry, 10(1), 45- 51.

Schneider, K. (1980). Las personalidades psicopáticas (8a ed). Madrid: Edições Morata.

Serpa Jr., O. D. (2007). Subjetividade, valor e corporeidade: os desafios da psicopatologia. In: Silva Filho, J. F. (Org). Psicopatologia Hoje (Coleções IPUB) (pp. 11-62). Rio de Janeiro: Contracapa.

Sonenreich, C., Kerr-Corrêa, F., \& Estevão, G. (1991). Debates sobre o conceito de doenças afetivas. São Paulo: Manole.

Stanghellini, G., Rosfort, R. (2013). Borderline depression: a desperate vitality. Journal of Consciousness Studies, 20(7-8), 153-177.

Tamelini, M. (2013). O processo psíquico sob a ótica Fenomenológica. Revista Psicopatologia Fenomenológica Contemporânea, 2(1), 91-102.

Tavares, H., \& Ferraz, R. B. (2011). Transtornos de personalidade. In: Miguel, E. C., Gentil, V. \& Gattaz, W. F. (Ed). Clínica Psiquiátrica, pp. 1051-1064. Barueri: Manole.

Tonus, A., Estevão, G., \& Sonenreich, C. (2012) Reconsideração dos conceitos: Transtornos de Humor (Afetivos). In: Rodrigues, A. C. T., Streb, L. G., Daker, M. V., Serpa Junior, O. D. (Orgs). Psicopatologia Conceitual, pp. 103-114. São Paulo: Roca 